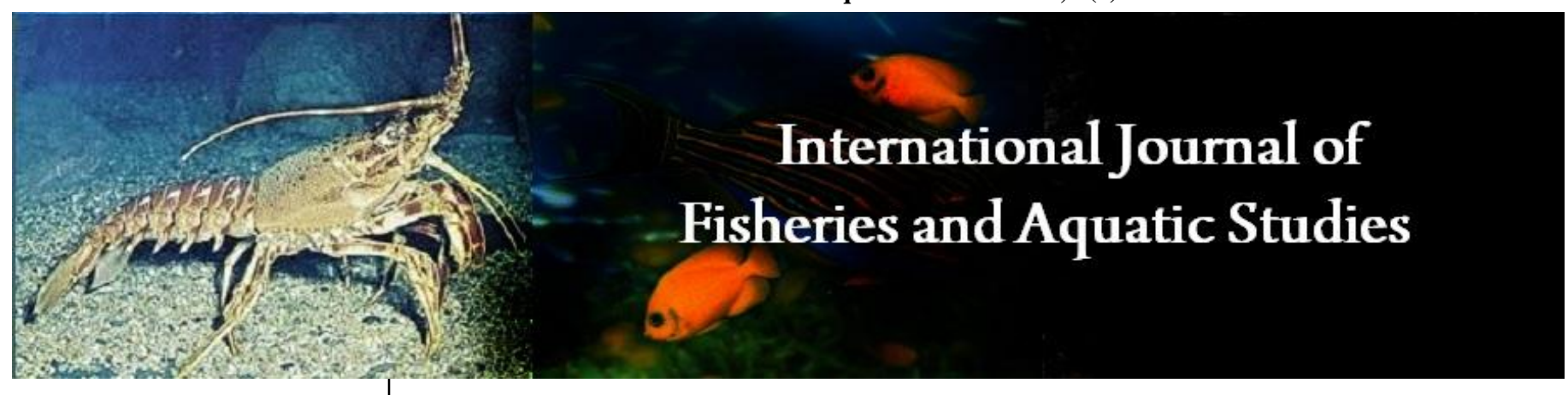

E-ISSN: 2347-5129

P-ISSN: 2394-0506

(ICV-Poland) Impact Value: 5.62

(GIF) Impact Factor: 0.549

IJFAS 2021; 9(2): 241-244

(C) 2021 IJFAS

www.fisheriesjournal.com

Received: $x x-01-2021$

Accepted: xx-02-2021

\section{N Daniel}

Institute of Fisheries Post

Graduate Studies (IFPGS),

TNJFU-OMR Campus, Chennai,

Tamil Nadu, India

\section{K Sathyaraj}

Institute of Fisheries Post

Graduate Studies (IFPGS),

TNJFU-OMR Campus, Chennai,

Tamil Nadu, India

\section{E Suresh}

Institute of Fisheries Post Graduate Studies (IFPGS),

TNJFU-OMR Campus, Chennai,

Tamil Nadu, India

\section{A Angela Mercy}

Institute of Fisheries Post

Graduate Studies (IFPGS),

TNJFU-OMR Campus, Chennai,

Tamil Nadu, India

\section{K Karal Marx}

Institute of Fisheries Post

Graduate Studies (IFPGS),

TNJFU-OMR Campus, Chennai,

Tamil Nadu, India

\section{A Uma}

Institute of Fisheries Post Graduate Studies (IFPGS),

TNJFU-OMR Campus, Chennai,

Tamil Nadu, India

\section{G Sathishkumar}

Institute of Fisheries Post Graduate Studies (IFPGS),

TNJFU-OMR Campus, Chennai,

Tamil Nadu, India

Corresponding Author:

N Daniel

Institute of Fisheries Post

Graduate Studies (IFPGS),

TNJFU-OMR Campus, Chennai,

Tamil Nadu, India

\section{Tobacco leaf dust as natural anaesthetic to GIFT tilapia}

\author{
N Daniel, K Sathyaraj, E Suresh, A Angela Mercy, K Karal Marx, A Uma \\ and G Sathishkumar
}

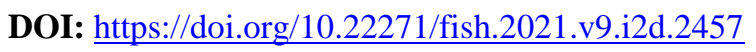

\section{Abstract}

The present study evaluated the anaesthetic activity of tobacco (Nicotiana tabacum) leaf dust in fish. GIFT tilapia was used as an experimental animal with the total study duration of 24 hours. The fish size of $4.58 \pm 0.68 \mathrm{~g}$ was randomly distributed into the 20-liter plastic tub at a stocking density of 10 fishes per container. Anaesthetics were added into experimental tubs of seven different groups viz. one control (0 $\mathrm{mg} / \mathrm{L})$, followed by six treatment groups $(25,50,75,100,125$ and $150 \mathrm{mg} / \mathrm{L})$ in triplicates. Results showed that an increase in the concentration of tobacco leaf dust shortened the induction time, but delayed the recovery time in fish $(p<0.05)$. There was no mortality observed in control (without sedative) and up to the dosage of 25 to $100 \mathrm{mg} / \mathrm{L}$, but after that mortality ensued from 6 to $16 \%$ in the groups exposed to a high dose of more than $100 \mathrm{mg} / \mathrm{L}(p<0.05)$. The temperature in the tanks showed no difference among all groups, while $\mathrm{DO}, \mathrm{pH}$, and $\mathrm{C} 02$ were affected by anaesthetics given $(p<0.05)$. The results of this study are encouraging that tobacco leaf dust has the potential to sedate the fish, and it minimizes the water quality concerns at a correct level. Based on the result of this study, tobacco leaf dust at the levels of 25 to $100 \mathrm{mg} / \mathrm{L}$ can be recommended to the fish farmers for safe and successful transportation of GIFT tilapia without causing the mortality.

Keywords: fish, induction time, mortality, natural sedative, Nicotiana tabacum, recommended dose, recovery time, water quality parameters

\section{Introduction}

Anaesthetics are mainly used for fish transportation to lower the active metabolism of fish by reducing oxygen uptake and decline the carbon dioxide and ammonia production ${ }^{[1,2,3,4]}$. It has also been used in the laboratory while handling the animals for vaccination, observation, and during the time of tissue and blood sampling. Anaesthetics are when used at appropriate dose reduces the metabolic rate, physiological stress, oxygen consumption, carbon dioxide, and ammonia production during transportation ${ }^{[5,6]}$, thereby reducing mortality during and after the transportation ${ }^{[7,8,9]}$. Research on anaesthetics in fish has been encouraged by many previous workers, and they standardized the optimal dose for sedation and safe transportation of some fishes ${ }^{[10]}$. Nevertheless, most of the researches were carried out on synthetic anaesthetics, which are generally costly and may carry some toxic effects to fish and require precaution while handling [11]. Due to these reasons, although an exploration and dose standardization of chemical anaesthetics were well explored, many are now encouraged towards searching nonchemical means of anaesthetizing fish ${ }^{[12,13,14]}$. It has been reported that the most commonly used chemical anaesthetic, tricaine methane-sulfonate commonly known as MS-222 demonstrated for its retinal toxicity in fish ${ }^{[15]}$ and suspected as a carcinogenic agent in human [16]. Therefore, investigations are vital to develop and popularise the use of viable natural anaesthetics alternatives to chemical sedatives. Therefore the present study was conducted to evaluate the potential of tobacco leaf dust as a natural source of anaesthetics to fish.

Tobacco is a common plant available throughout India, which potential as anaesthetics was not demonstrated in fish except rohu, Labeo rohita ${ }^{[17]}$. In fish, Labeo rohita, tobacco leaf dust gave promising results with the optimal dose of $25 \mathrm{mg} / \mathrm{L}$. However, data on the anaesthetic response of tobacco leaf dust in other fishes are currently unavailable, which justifies the necessity of conducting such study in other fishes. Since fish are species-specific, the results presented for one fish can't be generalized to other fishes. Therefore the present study was carried out. GIFT tilapia was used as an experimental animal in the present study since this 
fish is a popular fish, preferred for fish culture across the globe due to its faster growth and demand.

\section{Materials and Methods}

\subsection{Preparation of tobacco leaf dust}

The leaves of tobacco were collected from a retailer in Chennai. The collected leaves were washed properly using the distilled waters and dried in the room temperature for ten days. After drying, they were made into powder using the mixer, which was then used for conducting the experiment.

\subsection{Experimental fish and set-up}

Two hundred and ten (210) healthy animals with weight ranging from $4.58 \pm 0.68 \mathrm{~g}$ were used in the present study. Before initiating the study, animals were properly acclimatized and kept for 24 hours starving to minimize the excretion of wastes. The animals were then put it in an experimental plastic tank of 30-litre water capacity $(70 \mathrm{~cm} \mathrm{X}$ $50 \mathrm{~cm}$ ) filed with de-chlorinated freshwater. There were totally six different concentration of tobacco leaf dust used for the present study $(25,50,75,100,125,150 \mathrm{mg} / \mathrm{L})$ and one without sedative as control $(0 \mathrm{mg} / \mathrm{L})$. The experimental set-up was organized in triplicates. The induction time and recovery time were recorded using the digital stopwatch. Fish that lost balance and ceased movements of their opercula membrane (Anaesthetic phase) were removed immediately and transferred to fresh water for recovery. The recovery time was determined when the regular respiratory movement of the opercula starts again.

\subsection{Water quality parameter}

At the end of 24 hours, water samples from the experimental containers were collected, and temperature, $\mathrm{DO}, \mathrm{pH}$, and $\mathrm{CO}_{2}$ were examined. The temperature of the water was estimated using a thermometer. The dissolved oxygen, $\mathrm{pH}$, and $\mathrm{CO}_{2}$ values of the water were determined using the standard procedure ${ }^{[18]}$.

\subsection{Statistical Analysis}

The data were statistically analyzed using the statistical package of SPSS version 20.0 in which data were subjected to one-way ANOVA ${ }^{[19]}$ and Duncan's multiple range test ${ }^{[20]}$ to determine the statistical differences between the different groups. Comparisons were made at the $5 \%$ probability level.

\section{Results and Discussion}

3.1 Induction time, recovery time and percentage mortality of fish exposed to different concentration of tobacco leaf dust in the water

The present study demonstrated that tobacco leaf dust had an anaesthetic effect on GIFT tilapia. The induction time, recovery time, and percentage mortality of fish subjected to anaesthetics were influenced by tobacco leaf dust in an experimental animal (GIFT tilapia) which are represented in Table 1.

In the present study in GIFT tilapia, low dose $(25 \mathrm{mg} / \mathrm{L})$ of tobacco leaf dust added to water showed a delay in induction but a rapid recovery; whereas high dose (125-150 mg/L) exhibited quick induction but prolonged the recovery time $(p<0.05)$. The results of the present study indicate that an increasing the concentration of anaesthetics to water reduces the induction time and prolong the recovery time in fish. The result of this study is in line with the earlier reports in rohu (Labeo rohita) when tobacco leaf dust was used as a sedative
[17]. Also the trend noticed in the present study was similar to previous reports using different anaesthetics in Sea bass, Dicentrarchus labrax ${ }^{[21]}$; Rohu, Labeo rohita ${ }^{[22]}$; Senegalese sole, Solea senegalensis [23] ; Cobia, Rachycentron canadum $^{[24]}$; Seahorse, Hippocampus kuda [25]; Rainbow

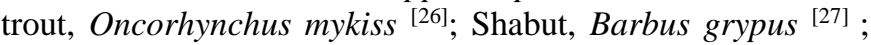
and Common carp, Cyprinus carpio ${ }^{[28]}$.

The present study displayed mortality $(p<0.05)$ only in the groups exposed to the higher concentration of anaesthetics $(125-150 \mathrm{mg} / \mathrm{L})$. There was no mortality recorded in the treatments with low doses $(25-100 \mathrm{mg} / \mathrm{L})$ and control. The result of the present study indicates that the mortality of fish happened only when fish exposed to the dosage exceeding its ideal dose. The higher mortality observed in the group subjected to higher anaesthetic dose $(125-150 \mathrm{mg} / \mathrm{L})$ during the study could be attributed to the combined effect of low DO levels, high $\mathrm{CO}_{2}$ in water (see Table 2) and toxic effect of tobacco leaf dust at higher concentration. The results corroborate with earlier authors who also reported that anaesthetics at higher dosage could cause mortality in Beluga, Huso huso [29]; Rohu, Labeo rohita [30]; and Clownfish, Amphiprion sebae ${ }^{[31]}$.

\subsection{Water quality parameters}

The water quality parameter of anesthetised water after 24 hours of an experiment in the present study shows variation $(p<0.05)$ except for temperature. The water quality parameters (temperature, $\mathrm{pH}, \mathrm{DO}$, and $\mathrm{CO}_{2}$ ) recorded during the present study is represented in Table 2.

The temperature of the water was not influenced $(p<0.05)$ by tobacco leaf dust $(p<0.05)$ in the present study. However, the result of the present study is contradictory to an earlier report in fish (Labeo rohita) using tobacco leaf dust as a sedative ${ }^{[17]}$. The conflicting results of this study might be attributed to the high water levels $(30 \mathrm{~L})$ maintained in the present study, which failed to increase the surrounding water temperature. This can also be explained in the sense that the heat generated by fish as a result of metabolic activity was not sufficient to influence the surrounding temperature.

The present study recorded the lowest level of dissolved oxygen (DO) in control, while the highest $(p<0.05)$ DO levels were manifested in the water that contains tobacco leaf dust. However, anaesthetics levels below $100 \mathrm{mg} / \mathrm{L}$ in water displayed higher $(p<0.05)$ DO level as compared to anaesthetics at higher dosages exceeding $100 \mathrm{mg} / \mathrm{L}$. The higher DO levels noticed in the anesthetized water is probably related to the less consumption of oxygen by fish due to sedation caused by tobacco leaf dust. The trends observed in the present study are consistent with previous results in the guppy, Poecilia reticulata [32]; and southern platy fish, Xiphophorus maculatus ${ }^{[33]}$ for an anaesthetic bath.

In the present study, the lowest $\mathrm{pH}$ levels were found in control, whereas all anaesthetic supplemented groups showed raised $(p<0.05) \mathrm{pH}$ levels. Within the treatments, the highest $\mathrm{pH}$ values were observed in the groups received the anaesthetic dose of 25 to $100 \mathrm{mg} / \mathrm{L}$ and the lowest $(p<0.05)$ $\mathrm{pH}$ values were seen in higher anaesthetic dose of 125 to 150 $\mathrm{mg} / \mathrm{L}$. Reduction of water $\mathrm{pH}$ in the control tank during the study was may be due to carbonic acid formation resulting from carbon dioxide release during fish respiration ${ }^{[34]}$. Low $\mathrm{pH}$ for the control group compared with that for the anaesthetic treated groups in the present study indicates the efficacy of anaesthetics in reducing carbon dioxide excretion and metabolic activity of the fish. 
In the present study, $\mathrm{CO}_{2}$ levels were highest in control and, lowest $\mathrm{CO}_{2}$ values were recorded in the treatments $(p<0.05)$. Within the treatments, groups exposed to higher anaesthetic doses (125 to $150 \mathrm{mg} / \mathrm{L})$ displayed higher $\mathrm{CO}_{2}$ content than that of animals subjected to lower (25 to $100 \mathrm{mg} / \mathrm{L})$ anaesthetic doses $(p<0.05)$. The increase in the survival of anesthetised fish from the present study could be interpreted as being a result of anaesthetics effect that reduced the fish metabolism resulting in less carbon dioxide excretion. The results of the present study are comparable with the available reports in the guppy (Poecilia reticulate), when 2phenoxyethanol was used as a sedative ${ }^{[2]}$. Low survival in the treatments of high anaesthetic doses during the study could be due to poor water quality. The un-anesthetized control group was not shown any mortality of fish, may be water quality deterioration alone can't influence the mortality of tilapia as they even can tolerate under poor water quality conditions.

Table 1: Concentration, induction time and recovery time of GIFT tilapia anesthetized with tobacco leaf dust

\begin{tabular}{|c|c|c|c|}
\hline Treatments & Induction time (Minutes) & Recovery time (Minutes) & Mortality (\%) \\
\hline Control $(0 \mathrm{mg} / \mathrm{L})$ & - & - & $0^{\mathbf{a}}$ \\
\hline $\mathrm{T} 1(25 \mathrm{mg} / \mathrm{L})$ & $18.36 \pm 0.07^{\mathbf{f}}$ & $1.36 \pm 0.07^{\mathbf{a}}$ & $0^{\mathbf{a}}$ \\
\hline $\mathrm{T} 2(50 \mathrm{mg} / \mathrm{L})$ & $15.69 \pm 0.24^{\mathbf{e}}$ & $1.70 \pm 0.18^{\mathbf{a}}$ & $0^{\mathbf{a}}$ \\
\hline $\mathrm{T} 3(75 \mathrm{mg} / \mathrm{L})$ & $12.33 \pm 0.06^{\mathbf{d}}$ & $2.33 \pm 0.13^{\mathbf{b}}$ & $0^{\mathbf{a}}$ \\
\hline $\mathrm{T} 4(100 \mathrm{mg} / \mathrm{L})$ & $10.57 \pm 0.27^{\mathbf{c}}$ & $3.24 \pm 0.12^{\mathbf{c}}$ & $0^{\mathbf{a}}$ \\
\hline $\mathrm{T} 5(125 \mathrm{mg} / \mathrm{L})$ & $8.38 \pm 0.11^{\mathbf{b}}$ & $4.01 \pm 0.23^{\mathbf{d}}$ & $6.66 \pm 3.33^{\mathbf{b}}$ \\
\hline $\mathrm{T} 6(150 \mathrm{mg} / \mathrm{L})$ & $6.33 \pm 0.11^{\mathbf{a}}$ & $5.04 \pm 0.23^{\mathbf{e}}$ & $16.66 \pm 3.33^{\mathbf{c}}$ \\
\hline
\end{tabular}

Data expressed as mean \pm SE $(n=3)$. Mean values in the same column with different superscript differ significantly $(p<0.05)$.

Table 2: Water quality parameters observed at different experimental conditions

\begin{tabular}{|c|c|c|c|c|}
\hline Treatments & Temperature $\left.\mathbf{(}^{\mathbf{0}} \mathbf{C}\right)$ & $\mathbf{D O}(\mathbf{m g} / \mathbf{L})$ & $\mathbf{p H}(\mathbf{m g} / \mathbf{L})$ & $\mathbf{C O}_{2}(\mathbf{m g} / \mathbf{L})$ \\
\hline Control $(\mathrm{mg} / \mathrm{L})$ & $30.33 \pm 0.33^{\mathbf{a}}$ & $6.32 \pm 0.11^{\mathbf{a}}$ & $6.23 \pm 0.08^{\mathbf{a}}$ & $19.00 \pm 0.57^{\mathbf{c}}$ \\
\hline $\mathrm{T} 1(\mathrm{mg} / \mathrm{L})$ & $30.33 \pm 0.33^{\mathbf{a}}$ & $8.16 \pm 0.14^{\mathbf{c}}$ & $7.73 \pm 0.23^{\mathbf{d}}$ & $11.33 \pm 0.66^{\mathbf{a}}$ \\
\hline $\mathrm{T} 2(\mathrm{mg} / \mathrm{L})$ & $30.33 \pm 0.33^{\mathbf{a}}$ & $8.01 \pm 0.20^{\mathbf{c}}$ & $7.63 \pm 0.29^{\mathbf{d}}$ & $11.66 \pm 0.88^{\mathbf{a}}$ \\
\hline $\mathrm{T} 3(\mathrm{mg} / \mathrm{L})$ & $30.66 \pm 0.33^{\mathbf{a}}$ & $7.87 \pm 0.14^{\mathbf{c}}$ & $7.56 \pm 0.17^{\mathbf{c d}}$ & $12.33 \pm 0.88^{\mathbf{a}}$ \\
\hline $\mathrm{T} 4(\mathrm{mg} / \mathrm{L})$ & $30.00 \pm 0.00^{\mathbf{a}}$ & $7.95 \pm 0.15^{\mathbf{c}}$ & $7.26 \pm 0.26^{\mathbf{b c d}}$ & $12.00 \pm 1.15^{\mathbf{a}}$ \\
\hline $\mathrm{T} 5(\mathrm{mg} / \mathrm{L})$ & $30.00 \pm 0.00^{\mathbf{a}}$ & $7.28 \pm 0.07^{\mathbf{b}}$ & $6.86 \pm 0.17^{\mathbf{b}}$ & $15.33 \pm 0.88^{\mathbf{b}}$ \\
\hline $\mathrm{T} 6(\mathrm{mg} / \mathrm{L})$ & $30.33 \pm 0.00^{\mathbf{a}}$ & $7.36 \pm 0.12^{\mathbf{b}}$ & $6.93 \pm 0.14^{\mathbf{b c}}$ & $15.00 \pm 0.57^{\mathbf{b}}$ \\
\hline
\end{tabular}

Data expressed as mean \pm SE $(n=3)$. Mean values in the same column with different superscript differ significantly $(p<0.05)$.

\section{Conclusion}

This study demonstrated that both induction and recovery time of fish with a response to tobacco leaf dust is concentration dependant. The anaesthetic concentration of up to 25 to $100 \mathrm{mg} / \mathrm{L}$ in water showed a sedative effect in GIFT tilapia without triggering mortality. According to the experimental data, tobacco leaf dust @ 25 to $100 \mathrm{mg} / \mathrm{L}$ may be recommended to fish farmers as a natural sedative for transportation.

\section{Acknowledgments}

Authors would like to extend their thanks to Vice-chancellor of Tamil Nadu Dr. J. Jayalalithaa Fisheries University (TNJFU), Nagapattinam, India for financial and technical support to carry out this work. Conducting of the experiment and handling of fish in the study complied with existing regulations of the country.

\section{References}

1. Boyd CE. Water quality management for ponds fish culture. Elsevier, Amsterdam 1982.

2. Teo LH, Chen TW, Lee BL. Packaging of the guppy, Poecilia reticulata, for air transport in a closed system. Aquacult 1989;78:321-332.

3. Harmon TS. Methods for reducing stressors and maintaining water quality associated with live fish transport in tanks: a review of the basics. Rev Aquacult 2009;1:58-66.

4. Pramod PK, Ramachandran A, Sajeevan TP, Thampy S, Pai SS. Comparative efficacy of MS-222 and benzocaine as anaesthetics under simulated transport conditions of a tropical ornamental fish Puntius filamentosus (Valenciennes). Aquac Res 2010;41(2):309-314.
5. Wedemeyer GA. Physiology of fish in intensive culture systems. New York: Chapman \& Hall, International Thompson Publishing 1996.

6. Ross LG, Ross B. Anaesthetic and sedative techniques for aquatic animals. Blackwell Science, Oxford, UK 1999.

7. Estudillo CB, Duray MN. Transport of hatchery-reared and wild grouper larvae, Epinephelus sp. Aquacult 2003;(1-4):279-290.

8. Hoskonen P, Pirhonen J. Temperature effects on anaesthesia with clove oil in six temperate-zone fishes. J Fish Biol 2004;64(4):1136-1142.

9. Cunha FEA, Rosa IL. Anaesthetic effects of clove oil on seven species of tropical reef teleosts. J Fish Biol 2006;69(5):1504-1512.

10. King WV, Hooper B, Hillsgrove S, Benton C, Berlinsky D. The use of clove oil, metomidate, tricaine methanesulphonate and 2-phenoxyethanol for inducing anaesthesia and their effect on the cortisol stress response in black sea bass (Centropristis striata L.). Aquac Res 2005;36:1442-1449.

11. Merck and Company. The Merck Index, 11th ed. 1606p. Rahway, New Jersey: Merck and Company 1989.

12. Ackerman PA. Morgan JD, Iwama GK. Les anesthésiques 2005.

13. Junior EFDM, Uehara SA, Rodrigues EC, Palheta GDA, Melo NFACD, Freire LDS, Takata R. Menthol and eugenol as natural anesthetics for early juveniles of curimba. R Bras Zootec 2018, 47.

14. Khumpirapang N, Pikulkaew S, Anuchapreeda S, Okonogi S. Alpinia galanga oil - A new natural source of fish anaesthetic. Aquac Res 2018;49(4):1546-1556.

15. Bernstein PS, Digre KB, Creel DJ. Retinal toxicity 
associated with occupational exposure to the fish anesthetic MS-222. Am J Ophthalmol 1997;124:843-844.

16. Maricchiolo G, Genovese L. Some contributions to knowledge of stress response in innovative species with particular focus on the use of the anaesthetics. Mar. Biol 2011;5:24-33.

17. Dinesh R, Prakash C, Chadha NK, Poojary N, Abraham S. Does tobacco (Nicotiana tabacum) leaf dust save the life of Rohu (Labeo rohita) fingerlings during transport. J Aquac Res Development 2017, 8(474).

18. American Public Health Association "APHA". Standard methods for the examination of water and wastewater Washington, DC: American public health association 1995, 21.

19. Cuevas A, Febrero M, Fraiman R. An anova test for functional data. Comput Stat Data Anal 2004;47(1):111122.

20. Duncan DB. Duncan multiple range test. Biometrics 1955, 11(1).

21. Mylonas CC, Cardinaletti G, Sigelaki I, Polzonetti-Magni A. Comparative efficacy of clove oil and 2phenoxyethanol as anaesthetics in the aquaculture of European sea bass (Dicentrarchus labrax) and gilthead sea bream (Sparus aurata) at different temperatures. Aquacult 2005;246:467-481.

22. Farid SM, Rahman MM, Shirin KK, Nur NN. Effect of clove oil as an anesthetic on Labeo rohita (Hamilton). J Agr forest Env 2008;2:1-6.

23. Weber RA, Peleteiro JB, García Martín LO, Aldegunde M. The efficacy of 2-phenoxyethanol, metomidate, clove oil and MS-222 as anaesthetic agents in the Senegalese sole (Solea senegalensis Kaup 1858). Aquacult 2009;288:147-150.

24. Gullian M, Villanueva J. Efficacy of tricaine methanesulphonate and clove oil as anaesthetics for juvenile cobia Rachycentron canadum. Aquac Res 2009;40:852-860.

25. Pawar HB, Sanaye SV, Sreepada RA, Harish V, Suryavanshi U, Ansari TZA. Comparative efficacy of four anaesthetic agents in the yellow seahorse, Hippocampus kuda (Bleeker, 1852). Aquacult 2011;311:155-161.

26. Yildiz M, Kayim M, Akin S. The anesthetic effects of clove oil and 2-phenoxyethanol on rainbow trout (Oncorhynchus mykiss) at different concentrations and temperatures. Iran J Fish Sci 2013;12(4): 947-961.

27. Ogretmen F, Gölbaşi S, Inanan BE, Kizak V, Kayim M. Use of clove oil and eugenol to anesthetize fingerling Shabut Barbus grypus. N Am J Aquac 2014;76(1):9-13.

28. Kamble AD, Saini VP, Ojha ML. The efficacy of clove oil as anesthetic in common carp (Cyprinus carpio) and its potential metabolism reducing capacity. Int $\mathrm{J}$ Fau Biolog Stu 2014; 1(6):01-06.

29. Hoseini SM, Ghelichpour M. Efficacy of clove solution on blood sampling and hematological study in Beluga, Huso huso (L.). Fish Physiol Biochem 2012;38:493-498.

30. Husen MA, Sharma S. Immersion of rohu fingerlings in clove oil reduced handling and confinement stress and mortality. Int J Fish Aquat Stud 2015;2:299-305.

31. Balamurugan J, Kumar TTA, Prakash S, Meenakumari B, Balasundaram C, Harikrishnan R. Clove extract: A potential source for stress free transport of fish. Aquacult 2016;454:171-175.

32. Teo LH, Chen TW. A study of metabolic rate Poecilia reticulata Peters, under different conditions. Aquacult Fish Manage 1993;24:109-117.

33. Guo FC, Teo LH, Chen TW. Effects of anesthetics on the oxygen consumption rates of platyfish, Xiphophorus maculatus (Gunther). Aquac Res 1995;26:887-894.

34. Swann L. Basic review of aquaculture. Iowa State University, Technical Bulletin Series 102, Ames 1992. 